\title{
"Next, it will be you": Women's fear of victimization and precautionary safety behaviors in informal settlement communities in Nairobi, Kenya
}

\author{
Samantha C. Winter ${ }^{1}$, Nathan Jason Aguilar ${ }^{1}$, Lena Moraa Obara ${ }^{2}$, and Laura Johnson ${ }^{3}$ \\ ${ }^{1}$ School of Social Work, Columbia University \\ ${ }^{2}$ School of Social Work, Rutgers, The State University of New Jersey \\ ${ }^{3}$ School of Social Work, Temple University
}

\section{Author Note}

Samantha Winter https://orcid.org/0000-0001-6629-7642

Nathan Jason Aguilar https://orcid.org/0000-0003-1861-007X

Lena Moraa Obara https://orcid.org/0000-0002-8161-6901

Laura Johnson https://orcid.org/0000-0002-1882-8186

Winter,

Correspondence concerning this article should be addressed to Samantha

Columbia University, 1255 Amsterdam Avenue, New York, NY 10027. Telephone: +1212-851-

2271. Email: scw2154@columbia.edu 


\section{Introduction}

Globally, over one billion people live in informal settlements (UN-Habitat, 2015b). In Africa, close to $60 \%$ of the urban population live in these settlements (UN-Habitat, 2015b) defined as residential areas lacking durable housing, sufficient living and public spaces, access to basic infrastructure and services, and secure tenancy (UN-Habitat, 2016). By 2050, the urban population in Africa is expected to triple, and UN-Habitat (2015a) estimates that of the 10 million people who move to cities each year, two-thirds end up living in informal settlements.

Cities are often characterized as areas of higher violence and crime. Some research has found that 60 to $70 \%$ of urban residents have been victims of crime in lower- and middle-income countries where urban population growth rates are the highest (UN-Habitat, 2016). Urban informal settlements, in particular, are often characterized as violent spaces with poor security (Izugbara \& Egesa, 2019; Ruteere et al., 2013; UN-Habitat, 2015b; Ziraba et al., 2011); yet, there is a paucity of research investigating resident's perception of these characterizations, particularly their fear of violence and crime, and the effect these perceptions have on their behaviors and experiences within their communities. Thus, the primary purpose of this study is to explore women's fear of victimization in informal settlements in Nairobi, Kenya, the types of crime and violence and the environmental factors that contribute to this fear and how fear of victimization influences women's behavior as they navigate their daily lives.

\section{Violence in Informal Settlements in Nairobi, Kenya}

Over $60 \%$ of the 3 million residents of Nairobi live in informal settlements (APHRC, 2014). There is limited research documenting actual violence or crime rates in these communities; however, findings from a study focused on injury deaths in two informal settlements in Nairobi found that $49 \%$ of injury deaths were intentional and $47 \%$ were a result of homicide (Ziraba et al., 2011). Findings from another study examining crime in Kibera, the largest informal settlement in Nairobi, suggested that $54 \%$ of respondents had experienced a crime in the year leading up to the study (Kubende, 2018). The most common types of crime 
reported were robbery $(28.7 \%)$ and pick pocketing (23.1\%). In another study conducted in four large informal settlements in four cities across Kenya, $98.8 \%$ of respondents reported witnessing a crime being committed in the previous three months, and the crimes individuals reported experiencing or being exposed to most frequently were theft (37.2\%), mugging $(23.3 \%)$, and robbery (16.2\%) (Musoi et al., 2014). Only $5 \%$ of residents in the study mentioned gender-based violence or murder. However, estimates from a 2002 survey in the greater Nairobi area suggest that, annually, one in four women may be a victim of physical, economic or emotional abuse or sexual harassment and over one in ten women may be sexually abused (Stavrou, 2002). These rates are expected to be higher in informal settlements.

One study focused specifically on interpersonal violence in one large informal settlement in Nairobi, for example, reported that up to $85 \%$ of women may experience IPV in their lifetime (Swart, 2012). Winter and colleagues (2020) found that about two-thirds of women in a random sample of women from another large informal settlement in Nairobi experienced IPV in the last year. Although research suggests that young men, especially those $15-25$ years, are the most likely to die as a result of violent crime, to be victimized, and to be perpetrators of homicide in informal settlements (Ziraba et al., 2011), women may be affected more by fear of violence or suffer under less visible forms of violence and crime (Doran \& Burgess, 2011).

\section{Perceptions of Safety and Fear of Crime and Violence}

Safety is a serious concern for residents of informal settlements in Nairobi (APHRC, 2014). In fact, data from a 2009 report suggest that up to two-thirds of residents in in these settlements do not feel safe (Oxfam GB, 2009). Research and theory suggest there are a variety of factors that influence perceptions, especially fear, of crime and violence. Demographic theories examine the extent to which fear of victimization is associated with individuals' experiences of crime or violence or feelings of vulnerability (Doran \& Burgess, 2011). The victimization hypothesis, for example, posits that one's personal experiences of crime and violence increases their sensitivity to risk or fear of victimization. Indirect victimization 
hypotheses, on the other hand, recognize that people can develop a fear of victimization through vicarious victimization, including hearing about or witnessing violence through media that exacerbates perceptions of risk of victimization; through interpersonal communication about violence; and through one's social network or community (Clark, 2003; Intravia et al., 2017). Additionally, vulnerabilities theories claims that different socio-demographic groups, such as women, non-whites, lower class, and elderly, experience higher levels of fear of victimization than other groups, where women's fear of sexual assault is especially pronounced (Rader, 2004).

Social theories explaining fear of victimization, namely social disorganization theory and related models such as subcultural diversity, social integration, community concern, and social change theory, posit that people's perceptions of crime and violence, especially their fear, reflect general societal- or community-level beliefs about crime, violence, insecurity, and risk caused by a change or breakdown in societal factors (Doran \& Burgess, 2011). Social disorganization theory is one of the most influential theories for understanding the spatial aspect of crime and violence and fear of victimization. Shaw and McKay (1942) developed social disorganization theory after discovering that crime rates were not evenly distributed across space. Rather, crime and disorder tend to be concentrated in specific areas and remain relatively stable in specific locations despite population changes (Parks, 2014). Social disorganization theory has been revised but, generally, suggests that when people live in areas with high rates of poverty, unemployment, economic insecurity, exclusion, and racial or ethnic heterogeneity they tend to be less trusting of others and experience a strain on community collective efficacy (Sampson, 2012). These burdens, coupled with a lack of resources, hinder one's ability to provide assistance to fellow residents in need or to come together for the common good of the neighborhood, e.g., for crime and violence reduction (Sampson, 2012).

Finally, environmental theories suggest that perceptions of crime and violence, sense of fear, and the behaviors people adopt in response, are linked to people's interpretation of the 
social and physical characteristics of the environment (Doran \& Burgess, 2011). Environmental dynamics and conditions have a profound effect on fear of victimization, especially for women (Hsu, 2010). Disorder/incivilities theories suggest that signs of disorder or visible cues in the environment indicate a breakdown in social norms of behavior, social controls, and support systems that trigger fear of victimization (Branas et al., 2011; Doran \& Burgess, 2011). Threatening and safe environments theories associate fear of victimization with specific physical or social cues in the environment, such as limited street lighting, poor visibility, overgrown vegetation, shadows, or lack of pedestrian activity that signify a threatening environment (Branas et al., 2018). Finally, the signal crimes perspective posits that the general social character of the environment shapes the way crime and violence are interpreted. For example, different crimes or disorder may be interpreted differently in various environments and by the communities and cultures that occupy that space, which, in turn, influences individuals' reactions or fear response (Innes, 2004).

Beyond theories that explore fear of victimization, it is essential to recognize that many of the challenges experienced in poor, often minority communities, including general perceptions and stereotypes of these communities and the residents who live there, are often the result of discriminatory laws, structures, institutions, and norms that were shaped decades if not generations ago, but still plague current residents. For example, informal settlements in Nairobi, and many of the challenges faced by residents of these communities, are, at least in part, a product of discriminatory colonial policies that have been perpetuated by persistent social and economic exclusion, stigmatization, and marginalization of these communities (Darkey \& Kariuki, 2013; Wanjiru \& Matsubara, 2017). In a forward to a 2002 Nairobi crime and violence survey, Anna Tibaijuka, the executive director of UN-Habitat in Kenya at the time, summed it up well when she stated, "urban crime and violence are not a spontaneous occurrence, but above all, the product of a society characterised by inequality and social exclusion. Measures that protect urban communities from deprivation, unemployment, 
homelessness, illiteracy and social disintegration will ultimately also protect them from crime" (Stavrou, 2002, p. 2).

\section{Fear of Victimization and Precautionary Safety Behaviors}

The early focus of fear of victimization research concentrated on the degree to which fear was seen to be irrational or rational when compared to the actual occurrence of crime and violence (Doran \& Burgess, 2011). However, fear of victimization is more pervasive than crime and violence and is linked to a number of negative psychological and physiological outcomes (Keane, 1998; Lorenc et al., 2012; Stafford et al., 2007)—suggesting that fear of victimization, itself, and the subsequent societal and health impacts are as important to study as crime and violence (Warr, 1985, 2000). Fear or victimization manifests itself in precautionary safety behaviors that residents use to avoid or defend themselves against crime and violence (Rader, 2004; Rader et al., 2007). Avoidance behaviors resulting from fear of crime and violence might lead residents to strategically navigate through their neighborhoods, shifting their schedules and routines in order to minimize the risk of victimization (May et al., 2010). Defensive behaviors are also developed and practiced as a result of fear of victimization. For example, a person fearing crime or violence may procure or carry a weapon or enhance security systems in their homes (Keane, 1998; May et al., 2010).

Given both the perceived and actual risk of violence that women face, fear of victimization greatly influences the way in which women navigate their environments (Doran \& Burgess, 2011). As such, women living in informal settlements—sites that have faced continuous social exclusion, marginalization, and persistent deprivation-may be fearful of their safety, which likely influences their everyday experiences, movements, and relationships to their environment. While some research focuses on women's perceptions of violence and safety planning strategies in Kenya, the focus has been within the context of intimate relationships (Gillum et al., 2018; Wood et al., 2019) as opposed to the broader community. As such, there is a paucity of research focused on women's fear of victimization and the ways in which this fear 
may influence their behaviors in informal settlements. This study sought to help fill this gap by exploring women's fear of victimization, the types of crime, violence, and environmental factors contributing to that fear, and how women's fear of victimization influence their behaviors within Mathare, a large informal settlement in Nairobi, Kenya.

\section{Methods}

\section{Study Site}

Data for this study were collected in Mathare, one of the largest informal settlements in Nairobi, Kenya, in 2016. Although the boundaries and population of Mathare are contested, estimates suggest the settlement is home to over 200,000 residents living in just under 3 -square kilometers-making it one of the most densely populated areas in Kenya (Kenya National Bureau of Statistics, 2019a). Just as the boundaries and population of the settlement are contested, the boundaries and number of villages within the settlement are also disputed. This research focused on the 11 villages that women in the study identified as comprising Mathare informal settlement.

Mathare is also one of the oldest informal settlements in Kenya with its earliest residents settling there in the 1920's, years before Kenya's independence from British colonial rule (Wanjiru \& Matsubara, 2017). The development of informal settlements in Nairobi is rooted in racist colonial policies of social and spatial segregation (Darkey \& Kariuki, 2013). Under colonial rule, Nairobi was intended to be a European settlement where African natives were considered temporary residents of the city. Only those who worked directly for the colonial government were considered legitimate city residents, and provided housing in restricted 'workers' housing' zones (Wanjiru \& Matsubara, 2017). Despite restrictions on African native migration into Nairobi, many still moved to the city in search of new economic and educational opportunities — settling on unused land in lowlands, flood plains, and waste dumps (Darkey \& Kariuki, 2013). There have been several attempts to demolish these informal settlements, but, after every attempt, 
more residents return. Today, over $60 \%$ of Nairobi residents live in informal settlements that take up less than $1 \%$ of the city's area and less than $5 \%$ of the residential area (APHRC, 2014).

Houses in Mathare are located along small streets and alleys. Conventional households are constructed with concrete and cement, concrete blocks, iron sheets, or stone with iron sheets or concrete roofing (Kenya National Bureau of Statistics, 2019b). While, historically, there were more men than women in informal settlements (Nelson, 1978), estimates of Mathare's population today suggest the number of males and females are almost equivalent (106,522 males:100,028 females) (Kenya National Bureau of Statistics, 2019a). Census estimates suggest that just over $47 \%$ of residents "in the labor force" (defined as those who are not full-time students, home-makers, retired, or incapacitated persons, and those who are not too young or too old to work) in Mathare are "working" and almost $13 \%$ are "seeking work," but are currently unemployed (Kenya National Bureau of Statistics, 2019b). Several studies suggest that the majority of residents in Mathare rely on informal economies for income, such as selling fruits and vegetables or mobile phone credit and basic household necessities, or casual labor 'gigs' including short-term construction jobs or clothes-washing and housework (Corburn et al., 2012; Darkey \& Kariuki, 2013; Kovacic, 2014; Lundine et al., 2012). For women, the environment in Mathare is considered unsafe by both residents and outsiders (Corburn et al., 2012; Darkey \& Kariuki, 2013; Winter et al., 2018).

\section{Data and Sample}

Qualitative data for this study were collected as part of a study investigating factors associated with women's access to space and services, especially water and sanitation, in Mathare, including women's perceptions of safety in their neighborhoods. In-depth, semistructured interviews were carried out with 55 female residents of Mathare over a period of 9months. The lead author of this study lived and carried out this research and other projects in Nairobi over a period of five years with support from graduate students from the University of Nairobi with expertise in conducting mixed-methods research. 
We used purposive sampling to recruit women for the study. First, the Chief of Mathare, village chairmen, and a local women's organization helped recruit women for introductory meetings about the study in each village. Women were provided information about the study and, if interested in participating, were asked to sign up and provide basic demographic characteristics, contact, and access to water and sanitation information. In informal settlements, access to water and sanitation is both a proxy for wealth (Rheingans et al., 2014) and utilization of neighborhood environments. Women in these settlements who lack access to water or sanitation services at home often rely on shared water points and/or public toilets that require them to navigate the greater neighborhood environment on a daily basis (Winter et al., 2019).

From the list of interested participants, a purposive sampling strategy was used to select women who represented a broad range of socio-demographic characteristics, such as employment and household wealth (keeping in mind that while the majority of residents in informal settlements live in poverty, there is heterogeneity in access to resources and income) and had varied daily movement throughout their neighborhoods. At least 5 women from each of the 11 settlement villages were interviewed, which yielded a total sample of 55 participants. Women in the study were required to be over the age of 18 years, residents of Mathare for at least 6 months (i.e., not visitors to the settlement), able to provide consent, and could speak Swahili or English. All participants provided written consent to participate.

During in-depth interviews, women were encouraged to speak openly about their experiences, uses, and avoidance of places and spaces; their access to resources and services (especially water, sanitation, rubbish disposal, employment opportunities); and their reasons for choosing to use or avoid spaces, places, and services throughout a 24-hour period. Follow-up questions and probes were used to clarify or ask for more detail.

\section{Analysis Strategy}

Interviews were audio recorded and then transcribed in full. Transcripts were analyzed using NVivo qualitative analysis software version 12 (QSR International, 1999). A modified 
grounded theory approach was used to guide the collection and analysis of the data. Preliminary reviews of the transcripts and the researchers' experiences conducing in-depth interviews with women, were used to develop a list of predefined codes and sensitizing concepts focused on women's perceptions and experiences of crime, violence, and security related to accessing and utilizing different places, spaces, and services in and between their villages. Two researchers - the first and third authors on this study—used this list to carry out cross-case, thematic analysis —adding their own codes and concepts as they reviewed and analyzed the transcripts. The two researchers reviewed each other's codes, concepts, and themes related to women's perceptions and fears of victimization in their villages. Regular discussions between the two researchers took place throughout and discrepancies in the researcher's codes and interpretations of the data were discussed until a consensus was reached according to best practices of qualitative research (Harry et al., 2005).

\section{Results}

\section{Participants}

Participants in this study ranged from 18 to 72 years old. Almost all of the women $(98 \%)$ had at least one child, and just under half were married. More than three-quarters of the women completed primary school, about one-fifth completed secondary and only one of the women never went to school. Over half of the participants had a business, but less than a quarter reported having steady, formal employment, or odd jobs (e.g., washing clothes). Although not all women knew their monthly household income, of those who did (76\%), 40\% reported monthly incomes between KES 5000 and 10,000 (about US\$50-100) and 33\% reported incomes below KES 5000. Over half of the women (53\%) lived in female-headed households.

\section{Women's Fear of Victimization}

Women in this study, regardless of whether or not they had been victimized, described a common fear of victimization among women living in informal settlements. They have all heard about, thought about, or, for some, experienced violence or attacks. For example, while 
Jennifer, herself, has never been attacked, she fears being attacked, “I don't know anybody [who has been attacked], we just fear it" (Jennifer, 7). Residents have learned to pay attention to their environments, listen for certain sounds, to avoid certain spaces and places, and to associate certain hours of the day with crime and violence. Our exploration of women's fear of victimization within their informal settlement communities yielded the following emergent themes: (1) the types of violence and crime women fear in informal settlements, (2) the factors, especially environmental (physical and social), that contribute to women's fear of victimization in these communities, and (3) the behaviors women adopt to minimize risk of victimization in informal settlements.

\section{Types of Violence and Crime Women Fear}

Respondents in this study talked about a variety of crimes and violence they, themselves, or women, in general, fear in informal settlements. Rape was the form of violence most frequently identified, but burglary, theft, general crimes, delinquency, murder, and IPV were also sources of fear for women.

Rape. Most women in this study did not share personal experiences of sexual assault or rape; yet, the possibility of being attacked came up as a source of underlying fear or concern for almost all the respondents. For example,

If you are a woman, very often a thief can decide to violate you in ways other than stealing from you. You'll run into someone who was intending to rob, but you are raped. That has never happened to me, but if you are a human being you have to fear and think through these possibilities (Eleanor, 11)

Many women in this study related stories they heard about cases of rape in informal settlements, which contributed to their fears about their own safety in their communities, e.g.,

The day before last, a person broke in, entered the house, and raped someone at night. Even the other day, another woman [was attacked]. A thief broke in while the husband 
was at work. He works as a security officer. He [the thief] entered, carried her to the river, and raped her there. (Susan, 10)

Several women also expressed fears that their children could be raped. For example, "A child who is in standard seven, if they meet her they will rape her. Meeting with people like that, we say, 'if they don't harm you, you are just lucky'” (Nancy, 1). Women's fears were reinforced by stories of recent cases of children being raped or attacked in the settlement. For example, "the other day, there was a child who disappeared. We were looking for her. After two weeks, we found her. She had been raped and killed" (Carol, 8). For some women, the fear of rape was compounded by fears of contracting sexually transmitted infections, particularly HIVIAIDS, or a potential unwanted pregnancy, e.g., "If a woman runs into those men at night they will struggle, rape her, impregnate her. She will decide to abort the pregnancy. The baby will die and she will die because it was an unwanted pregnancy" (Florence, 5).

Burglary. Respondents also reported burglary as a serious concern for women living in informal settlements. While most women did not report having personally experienced sexual violence, many did share openly about having their houses burgled-sometimes more than once. Julia, for example, recalls:

I have been robbed several times... They broke in when I wasn't home, took my TV and DVD twice, and then, there was a time they tried breaking in at night when we were asleep. So, it was good luck that I was awake, I screamed and they took off. And then, my neighbor has been broken into twice at night. (Julia, 10)

Burglary, unlike other crimes participants described, seem to be carried out largely during the day when people are not at home, e.g., "you find that people who live in our plot go to work, including myself. So, most people are not there during the day, by the time you come back home you find that someone broke into your house and stole your things" (Millicent, 8).

Robbery. Respondents also talked about robbery as a source of fear or concern for women living in informal settlements. For example, "There are a lot of thieves even during the 
day" (Anna, 5) or "I fear running into thieves" (Dorcas, 6). Many women described robbery as something violent that takes place outside the home-in the alleyways, out on the road, on the way to a toilet, coming home from work, or returning from visiting friends or family, with some suggesting thieves follow or carry women to their homes.

Assault with a Weapon. One of the most serious forms of victimization respondents described as a source of fear for women in informal settlements was assault with a weapon. Respondents talked about a general fear of being attacked with a weapon and, potentially, being killed. As with other forms of victimization women described, the fear of being attacked or killed, is particularly pervasive at night. Elena, for example, described how a recent murder in her area reinforced her fear of going out at night:

Around here you can find a person who has been killed. Like the other day, we found a person who was dumped there [on the side of the road]. He had been killed. These are horrible stories. Another young person was strangled and dumped there at the river. If you see that, you cannot go outside. You think, next, it will be you. (Elena, 7) Interpersonal Violence. Although very few women discussed IPV in the context of conversations around perceived safety some women pointed out that this is a serious issue in informal settlements. Although no one provided a personal anecdote about their own experiences with IPV, Clarice provided a description of a woman she had assisted who had experienced recent IPV:

Yesterday as I was walking along doing that research, I met a young lady that was beaten, beaten, beaten and was bleeding so I approached her and asked her what is happening. Then she narrated the story to me that she had been beaten by the boyfriend. (Clarice, 1)

Results suggest that the majority of women living in this informal settlement likely have some fear of being attacked or victimized. Even the few women who stated they felt safe or, at the very least, they felt they were "used to" living in the settlement, recognized that women, in 
general, fear the possibility of being victimized in informal settlements. Respondents' individual drivers of fear, however, differ.

\section{Geography of Fear-Environmental Factors Influencing Women's Fear}

Respondents' descriptions and characterizations of their informal settlement communities suggest that, in addition to the type of crimes and violence occurring in informal settlements, space and place and the way people use those places/space contribute to women's fear of victimization or their sense of safety in these communities.

Informal Settlement Versus Non-Informal Settlement Communities. Several women in the study compared their sense of safety and/or fear of victimization while living in an informal settlement community to experiences they had living in non-informal settlement communities. Carol, for example, compared her perceptions of safety in Huruma-a slightly higher-income neighborhood—with her experience in Mathare—suggesting that, despite being just across the street from the informal settlement, security in Huruma was seemingly much better than in Mathare, e.g., "You know, I used to live there in Huruma in a house of iron sheets. We used to pay money for security. The youth were part of a group that were watching [the houses]. They would come and collect their money. They, even us, were the security. There is nothing like that in Mathare (Carol, 7).

Between Village Differences. Many respondents also suggested that women's sense of safety and fear of victimization in informal settlements are affected by the villages in which they reside, e.g.,

In our village its dangerous to step out at night. If you step out at night, you will meet with thieves, drunkards, because of that it's not safe for to go out at night (Susan, 5).

Other women emphasized that they fear certain types of crime or violence in specific villages, e.g., "There is a lot of raping going on in this village and they are youths. Sometimes, if you stay alone, you can't get out of your house because they will rape you" (Mary, 10) 
Village Dynamics. While some women talked about fearing crime and violence within their own villages, several characterized other villages in the settlement as dangerous. Helen, for example, describes village $3 \mathrm{C}$ as a dangerous place to live, particularly for a person belonging to the Luo tribe-suggesting that the geography of women's fear of victimization and sense of safety in informal settlements may be linked to conflict between tribes/ethnic groups, particularly when incited by politicians during election periods:

I was in $3 \mathrm{C}$, but then there was a lot of chaos down there.... People were being killed, houses were being burnt; so, insecurity made me move from $3 \mathrm{C}$ to come to Namba 10. In Namba 10, here, we are Luos. Many people who are staying here are Luos. Down there, in $3 \mathrm{C}$, we were a mixture of people and tribes...I got attacked because of my tribe.... In Namba 10, here, only during elections is when we get worried (Helen, 3). Some women also talked about how security and police composition vary by village-affecting the dynamics and their sense of safety within those communities. For example, "if you go to some areas, you will find there are police and there is security in that area. Now this area, you will see, there is conflict" (Dorcas, 6). Some women also suggested that the efficacy of community-led security initiatives varies by village. All of these village dynamics seem to affect women's fear of victimization and sense of safety in their informal settlement communities.

Crime Hotspots. In addition to village-level variations in security and violence, and in women's fear of victimization or sense of safety, respondents labeled specific spaces and places as "hotspots" for crime and violence in their communities. Toilets, in particular, were characterized as places women feared to go in their communities, especially at night, e.g., "going to the toilet at night is as if you are seeking death. That place is bad." (Caroline, 7). Candice described one toilet, in particular, that was closed down because it was a hotspot for rape, "There was one toilet that was closed down there in Kosovo due to rape cases when ladies enter the toilet men are allowed to mingle around here pretending they are cleaning or mopping and that's not the true story" (Candice, 1). 
Alleyways, referred to as "vichochoro" in Swahili, were another place/space women feared, i.e., "now the problem is the alleyways, you might find someone who will attack you" (Eleanor, 11) or "Let's say you are a young woman like this...it is at night and...she meets with the thieves between the narrow corridors where she is raped" (Faith, 1). Some women feared pathways or roads, e.g., "there is this one path/street, if you pass through there, even if you are a young girl, you will be robbed" (Catherine, 4). Christine, like many women in the study, associated violence and crime with idle youth hiding in alleyways and on the streets, "The youth hide themselves in the alleyways, when the police leave, they return to the streets (Christine, 6)."

Women also identified specific geographic sites or businesses as hotspots, e.g., "right here, where we live, there is security, but, I hear, if you go there, to Bonde, even during the day, you will be robbed" (Bendettah, 10) or "that alcohol [illicit brew], you see, it comes from here. It is made here and supplied from here. When someone comes from outside and enters here...they fear" (Mary, 6).

Sounds in the Environment. Women's descriptions suggest that fear of victimization is pervasive and, for some women living in informal settlements, it is in the very atmosphere. For some, even the sounds of the neighborhood can reinforce perceptions and fears of crime, violence, and lack of safety. For example, "I hear people screaming at night. That alone will make you fear to go outside at night," (Helena, 2). Screaming, dogs barking, or even the sounds of footsteps or someone approaching, as Marta describes in the following excerpt, are often an indication to women that something "bad" might happen:

Once you hear someone else you feel like running, that's one of the reasons to be afraid. I don't know if those people are still outside there or maybe it is another group of people and am not sure what their intentions are, so that makes me more afraid (Marta, 2). 
Dangerous Places without Safety Features. Respondents indicated that features of the built environment, specifically security lights and gates, helped a space feel safe. An absence of these features added to their fear of victimization, "one main thing that causes insecurity is we have no gate" (Naomi, 7) or "the plot is very dark because there are no security lights outside...There might have been somebody just seated in the darkness...so you feel like...I cannot go to the back during the night" (Shai, 9). Some respondents implied that the way in which these features are used (or not) can also affect their fear, e.g. "Now that both gates are open there is a throughway. You don't know if that person has exited [the plot]. Maybe he has broken into your house, taken something, and gone" (Millicent, 8).

Safe Spaces and the Role of People. In addition to categorizing specific places as dangerous or violent, respondents also classified certain places/spaces as safe areas where they feel comfortable even late at night. Faith, for example, felt comfortable walking around late at night in her area because there are places where people are present 24-hours a day, e.g., "at least here issues of insecurity are not so rampant like in $3 \mathrm{C}$ where you can't go outside your house at $8 \mathrm{pm}$. Here you can come home even at midnight. Here at the petrol station there are youth washing cars throughout [the night]; so, you can come home" (Faith, 1). Similarly, Millicent describes a time when her housing plot felt safe because of the presence of many people, "Back then security was good, that's when I had just moved here and there were many people in this plot. Women were safe" (Millicent, 8).

\section{Fear of Crime Shapes Behavior}

Although very few participants in this study reported having actually been the victims of crime or violence, particularly the more severe forms of assault and rape, the fear of victimization, alone, seems to be one of the most prominent factors in women's decisions about how to manage their daily tasks, how and when to use or avoid certain spaces and places, where to live and when to leave, and how they perceive the environment around them. In fact, 
results from this study suggest women may adopt a number of avoidance and/or defensive behaviors to minimize their exposure to risk in informal settlements.

Avoid Going Outside at Night. Almost all study participants stated that that they do not go outside at night-a common avoidance behavior for women who fear victimization, e.g., "Like at night it is hard to go out for fear of being attacked" (Rose, 11).

Avoid Certain Places/Spaces. According to women in this study, accessing a toilet outside the home at night can be especially challenging, with some women staying inside at night and utilizing alternative methods of managing urination and defecation within the home to avoid being attacked, e.g., "we are not used to going to the toilet at night because there is no security around here...They are outside there, by the road. So, it is a must you use "the inside method" [a bucket inside the house], then you pour it outside" (Pauline, 8).

Hypervigilance and Mistrust. While many women said they simply avoid going outside at night most of the time, several have adopted other strategies for trying to avoid being attacked when outside their homes. For some, going outside requires a heightened awareness and quick reflexes, i.e.,

Maybe you wake up like 5 am in the morning and you go to the toilets...A few days ago, two girls reported that they met with some of those criminals somewhere, they had to hide until they passed (Nancy, 1).

Some women suggested that the atmosphere of insecurity in Mathare creates not only a hypervigilance, but a sense of mistrust among residents that adds to their fear, e.g., "if they find us sitting in the house at around 7 in the evening, maybe we had opened the house to let fresh air in, or maybe you are having supper or maybe cooking, they just come direct. I wonder sometimes if someone directs them where exactly to go. They come and take anything they want and leave" (Catherine, 4). Even small acts of delinquency serve to reinforce the mistrust, e.g., "even if you hang your clothes out on the line [to dry] someone will steal them. You are 
shocked they stole those things. That is what makes me feel there is no security in this place" (Priscilla, 8).

Defensive Communication. For other women, the strategies are more direct or defensive. Marta, for example, describes an experience she had in which she was able to adapt her language and way of speaking to talk her way out of a potential robbery:

I was going to search for water because there was a severe water scarcity, and because I did not want to deal with the chaos and fighting with other women and girls during the day I decided to go at night. That's when those three young men found me. They were asking me for my phone, cash or anything else. I sweet talked them so they left me alone. I just told them that I am their mother... if I was harsh to them, they could have harmed me but I did what I did to get out of that situation (Marta, 2).

Defensive Actions. Several women in this study pointed out additional strategies they have adopted to minimize being assaulted, attacked, or burgled. For some, this is a matter of ensuring the doors of the house are locked at all times. For other women, strategies involved enhanced fortification of their homes. For example, Julia suggests adding chairs to block the door to prevent thieves from entering, "It's not just a padlock. They use special kind of metal bar, they push the door then they enter. so, when you close the door then add chairs on top of that" (Julia, 10)

Teaching the Next Generation How to Protect Themselves. Respondents discussed how fear of certain spaces and places in settlements influence women's decisions about when and how to move through them. Even children are taught how to navigate their communities: "There is a high possibility of children getting into problems. As parents we advise the children on which streets to follow and also tell them to make sure they walk home with friends after school" (Millicent, 8). Despite women's careful analysis of their environments and their precautionary safety behaviors for moving through those spaces, women are constantly 
reanalyzing and reformulating strategies to move through their communities safely and to teach their children how to do so.

\section{Discussion}

In this study, we sought to explore women's fear of victimization through the narratives of women who live in informal settlement communities in Nairobi, Kenya. We investigated how women's perceptions of crime and violence influence fear of victimization and everyday experiences of, relationships to, and behaviors in the settlement environment. Violence and crime are serious fears for women in these communities. Rape emerged as the most common fear among women, which is consistent with both fear of victimization literature that suggests that women's fear of rape "shadows" their fear of other crimes (Rader et al., 2007) and with literature that suggests prevalence of rape may be higher in informal settlements than in other communities (Oduro et al., 2012). Fear of burglary, theft, general crimes, delinquency, murder, and IPV also emerged. These fears have very real implications for women's experiences and perceptions of their communities, and their ability to function within and navigate informal settlements. Indirect communication or the narratives that residents share with each other about violence and crime and cues in the environment, both physical and social, emerged as important factors in women's fear of victimization—giving us clues about how fear of victimization may be better understood in informal settlements and providing key points for intervention. In addition, findings suggest women's fear of victimization may have serious implications for their behavior, health, and well-being in these communities.

When talking about women's fear of victimization and crime and violence in informal settlements, more broadly, we think it's critically important to first acknowledge the role marginalization, exclusion, oppression and disinvestment in these communities may play in creating fear of and within informal settlements; so, we begin there. Because of the high rates of poverty, lack of policing, and unfavorable living conditions in informal settlements—conditions some scholars, e.g., Fox (2014), argue, and we agree, is a result of colonial era patterns of 
disinvestment and persistent government failure to cultivate effective institutions in informal settlements-these communities are often characterized as or presumed to be unsafe (Izugbara \& Egesa, 2019; Muggah, 2014; UN-Habitat, 2007). This perception of informal settlements as communities of violence and crime has led to harmful assumptions about the residents living in these settlements (Izugbara \& Egesa, 2019; Muggah, 2014). We hope that focusing on residents' descriptions of safety and fear of victimization within informal settlements will provide an opportunity to not only explore the nature and relevance of these characterizations from the perspectives of women who actually live there, but to also interrogate sweeping generalizations and assumptions about crime and violence in these communities and to demonstrate women's resilience in adopting strategies to keep themselves and their families safe despite persistent political and institutional disinvestment in or undermining of the safety and protection of residents of these settlements.

One of the leading theories in fear of victimization literature, called indirect victimization, hypothesizes that people can experience vicarious victimization when they observe or hear about another person's experience of violence or crime, which can enhance their fear of being victimized, personally (Doran \& Burgess, 2011). Research suggests, in particular, that recent and repeated indirect victimization is associated with fear of victimization (Russo \& Roccato, 2010). Findings from this study seem to corroborate this hypothesis-suggesting that the role of story or interpersonal communication of crime and victimization may play a key role in women's fear of victimization and perceptions of crime and violence within informal settlements. Only a few women in this study, for example, reported having been the victim of a crime such as burglary or theft; yet, nearly every woman in this study had heard stories about someone else's victimization or about violence and crime, in general, in their communities. According to almost all of the respondents, these anecdotes contributed to their own fears about victimization in their communities. 
Interestingly, interpersonal communication, also emerged as an important strategy some women adopt to protect themselves and/or their children from victimization. For example, Marta, a respondent in this study, suggested that she was able to use "sweet talking" to coax some attackers into letting her go and several women talked about using story or interpersonal communication to teach their children about how to avoid victimization. These findings suggest that while interpersonal communication or story may play a key role in exacerbating fear of victimization, it may also play an important role in women protecting themselves and their children from victimization in informal settlements.

Another category of theories explaining fear of crime and violence in the literature, called threatening and safe environment theories, focus on associations between characteristics or cues in the social and physical environment that trigger fear of crime (Doran \& Burgess, 2011). While there is a growing body of literature exploring these threatening and safe environments theories, few studies have explored environmental cues that trigger fear of crime in different environments, specifically informal settlements (Doran \& Burgess, 2011). Findings from this study suggest that there are a number of characteristics of and places and spaces within informal settlement environments that seem to trigger women's fear of crime and violence. And, importantly, descriptions of these characteristics, places, spaces, and cues help pinpoint possible areas or strategies for intervention.

Women's comparisons of their experiences living in non-informal settlements with their experiences living in an informal settlement or in comparing their own villages to other villages within Mathare, for example, helped to identify some potential cues associated with women's fears of victimization in informal settlements. The absence of community-led security and formal security (e.g., policing) and higher levels of drunkards, thieves, and idle youth, in particular, seemed to emerge as important factors associated with higher level of fear of victimization in some communities compared to others or in informal settlement communities compared to noninformal settlement communities, more broadly. Ethnic heterogeneity within villages, particularly 
during presidential elections when political tribalism has been incited by politicians to canvass for support in informal settlements (Shilaho, 2018), also emerged as an important socioenvironmental cue triggering women's fear of victimization. While tribalism, particularly incitement of tribalism for political gain, is a complex issue in Kenya (Shilaho, 2018), the timing of this trigger is predictable and, therefore, a targeted moment for intervention.

Several women in the study also identified geographic hotspots for crime and violence, including public toilets, alleyways, and alcohol distribution centers. These findings suggest that improved access to services like water, sanitation, and electricity within women's homes or plots and additional security in toilets or alleyways might help women to feel more comfortable and reduce crime and violence in these hotspots (Brown-Luthango et al., 2017; Dalu \& Manyani, 2020). Based on findings from this study, the addition of security lights and installation and consistent use of gates might also help women to feel safer in these communities. Finally, the presence of people, including informal security guards and workers, seems to also enhance women's sense of safety and reduce their fear of victimization in informal settlement communities. Efforts to support businesses like petrol stations that provide employment and, if operating during evening and night hours, a sense of safety and protection for women moving through these spaces, might help to reduce fear of victimization in informal settlement communities in interesting ways.

While women did not, specifically, talk about how personal experiences and/or hearing about others' experiences of crime and violence affected their mental health or well-being, fear of victimization is its own form of psychological violence and has a number of consequences for women's health and well-being and their ability to manage their daily tasks (Doran \& Burgess, 2011; Nussbaum, 2005). Research has identified several responses to fear of victimization which include an emotive response, a cognitive response, and a behavioral response (Rader, 2004)_all of which influence women's daily lived experiences. In a review of theoretical and empirical literature linking crime, fear of victimization, the social and built environment, and 
health and wellbeing, Lorenc et al. (2012) proposed that fear of victimization affects health and well-being in four ways: (1) anxieties induced by fear of victimization affect mental health; (2) poor health and mental health exacerbate fear of victimization; (3) fear of victimization can result in avoidance behaviors that can affect social interaction and physical health and activity; and (4) fear of victimization affects social wellbeing.

Findings from this study seem to corroborate these theories of fear of victimization that suggest, for example, that women who fear being victimized adopt precautionary safety behaviors, such as adding locks to doors and avoidance behaviors such as staying home at night or avoiding certain places and spaces (e.g., alleyways or public toilets) (Rader et al., 2007). Findings from this study and others (Winter et al., 2018) also indicate that women, fearing victimization, may avoid going outside at night, even to access toilets. Instead women rely on buckets or plastic bags that are emptied into nearby open drainages in the morning, which has serious implications for women's health and the environment. Avoiding going outside at night to use a toilet can cause physical health issues including urinary tract infections and/or constipation associated with withholding food or water and/or retaining urine and feces to minimize the need to go to the toilet (Fisher, 2006; O'Reilly, 2010; Sahoo et al., 2015). Furthermore, anxiety and psychological distress associated with the constant fear of victimization also affects women's overall mental health and well-being, which, in turn, may augment their fears. In addition to the negative emotional and health consequences of fear of victimization, adoption of avoidance and defensive behaviors reduce women's participation in social activities_-depriving them of social and personal rewards (Rader et al., 2007). And while findings from this study show how resilient women in these settlements are, they also raise questions about the systems that have failed-leaving women to have to develop strategies on their own to protect themselves and feel safe. Furthermore, as findings from this study suggest, women may also bear the responsibility for instilling a fear of victimization and strategies to 
avoid victimization in their children-a heavy responsibility for both mothers and children to bear.

Although the findings from this study provide important information about women's fears and perceptions of crime and violence in informal settlements, the study has limitations. The data collected are cross-sectional; so, we cannot make any claims about measurable fluctuations in crime, violence or women's perceptions across time. Data for this study were collected during 2016 — a little more than one year prior to the scheduled Kenyan presidential elections and during a time when corruption had been discovered in the NYS program; thus, women's perceptions of safety may have been affected by these circumstances. Additionally, we collected data only in Mathare informal settlement; thus, findings may not be generalizable to all informal settlements.

\section{Conclusion}

The purpose of this study was to explore women's fear of victimization within Mathare, an informal settlement in Nairobi, Kenya, the crimes and factors that contribute to this fear, and how fear of victimization influences women's behaviors in these settlements. Findings from this study revealed certain types of crime and violence, environmental cues, and interpersonal communication factors that contribute to women's fear of victimization. The findings also highlight ways women in Mathare have found to cope and to adapt their behaviors that allow them to continue to function and protect their children within their informal settlement communities despite fearing victimization, but, likely, at a cost to their health and well-being. There is a critical need for more research focused on social, economic, structural, community, infrastructure, technological, and individual strategies to prevent violence, enhance residents' sense of safety, and, subsequently, minimize women's fear of victimization in informal settlements. 


\section{References}

APHRC. (2014). Population and Health Dynamics in Nairobi's Informal Settlements: Report of the Nairobi Cross-sectional Slums Survey (NCSS) 2012.

Branas, C. C., Cheney, R. A., MacDonald, J. M., Tam, V. W., Jackson, T. D., \& Ten Have, T. R. (2011). A difference-in-differences analysis of health, safety, and greening vacant urban space. American Journal of Epidemiology, 174(11), 1296-1306.

Branas, C. C., South, E., Kondo, M. C., Hohl, B. C., Bourgois, P., Wiebe, D. J., \& MacDonald, J. M. (2018). Citywide cluster randomized trial to restore blighted vacant land and its effects on violence, crime, and fear. Proceedings of the National Academy of Sciences, 115(12), 2946-2951.

Brown-Luthango, M., Reyes, E., \& Gubevu, M. (2017). Informal settlement upgrading and safety: experiences from Cape Town, South Africa. Journal of Housing and the Built Environment, 32(3), 471-493.

Clark, J. (2003). Fear in fear-of-crime. Psychiatry, Psychology and Law, 10(2), 267-282.

Corburn, J., Ngau, P., Karanja, I., \& Makau, J. (2012). Mathare Zonal Plan Nairobi, Kenya:

Collaborative Plan for Informal Settlement Upgrading.

Dalu, M. T., \& Manyani, A. (2020). Gender Inclusivity and Development in South African Public Urban Spaces. In Urban Geography in South Africa (pp. 239-250). Springer.

Darkey, D., \& Kariuki, A. (2013). A study on quality of life in Mathare, Nairobi, Kenya. Journal of human ecology, 41(3), 207-219.

Doran, B. J., \& Burgess, M. B. (2011). Putting fear of crime on the map: Investigating perceptions of crime using geographic information systems. Springer Science \& Business Media.

Fisher, J. (2006). For her it's the big issue: putting women at the centre of water supply, sanitation and hygiene. Water, Sanitation and Hygiene Evidence Report. 
Fox, S. (2014). The political economy of slums: Theory and evidence from Sub-Saharan Africa. World Development, 54, 191-203.

Gillum, T. L., Doucette, M., Mwanza, M., \& Munala, L. (2018). Exploring Kenyan women's perceptions of intimate partner violence. Journal of interpersonal violence, 33(13), 2130 2154.

Harry, B., Sturges, K., \& Klingner, J. (2005). Qualitative data analysis: Mapping the process. Educational Researcher, 34(2), 3-13.

Hsu, H.-P. (2010). How does fear of sexual harassment on transit affect women's use of transit? Proc., Women's Issues in Transportation: Summary of the 4th International Conference, Innes, M. (2004). Signal crimes and signal disorders: Notes on deviance as communicative action 1. The British journal of sociology, 55(3), 335-355.

Intravia, J., Wolff, K. T., Paez, R., \& Gibbs, B. R. (2017). Investigating the relationship between social media consumption and fear of crime: A partial analysis of mostly young adults. Computers in Human Behavior, 77, 158-168.

Izugbara, C. O., \& Egesa, C. P. (2019). Young men, poverty and aspirational masculinities in contemporary Nairobi, Kenya. Gender, Place \& Culture, 1-21.

Keane, C. (1998). Evaluating the influence of fear of crime as an environmental mobility restrictor on women's routine activities. Environment and Behavior, 30(1), 60-74.

Kenya National Bureau of Statistics. (2019a). 2019 Kenya Polulaiton and Housing Census: Volume II Distritution of Populaiton by Administrative Units.

Kenya National Bureau of Statistics. (2019b). 2019 Kenya Population and Housing Census: Vol IV Distribution of Populaiton by Socio-economic Characteristics.

Kovacic, P. (2014, October 24). Mathare Demographic. Mapping: (No) Big Deal: Making the Invisible Visible.

Kubende, H. S. (2018). Factors influencing crime in the urban informal settlements: A case study of Kibra University of Nairobi]. Nairobi, Kenya. 
Lorenc, T., Clayton, S., Neary, D., Whitehead, M., Petticrew, M., Thomson, H., Cummins, S., Sowden, A., \& Renton, A. (2012). Crime, fear of crime, environment, and mental health and wellbeing: mapping review of theories and causal pathways. Health \& place, 18(4), 757-765.

Lundine, J., Kovacic, P., \& Poggiali, L. (2012). Youth and digital mapping in urban informal settlements: Lessons learned from participatory mapping processes in Mathare in Nairobi, Kenya. Children Youth and Environments, 22(2), 214-233.

May, D. C., Rader, N. E., \& Goodrum, S. (2010). A gendered assessment of the "threat of victimization": Examining gender differences in fear of crime, perceived risk, avoidance, and defensive behaviors. Criminal justice review, 35(2), 159-182.

Muggah, R. (2014). Deconstructing the fragile city: exploring insecurity, violence and resilience. Environment and Urbanization, 26(2), 345-358.

Musoi, K., Muthama, T., \& Kibor, J. (2014). A study of crime in urban slums in Kenya: the case of Kibra, Bondeni, Manyatta and Mishomoroni slums.

Nelson, N. (1978). Dependence and independence: Female household heads in Mathare Valley, a squatter community in Nairobi, Kenya SOAS University of London]. London, United Kingdom.

Nussbaum, M. C. (2005). Women's bodies: Violence, security, capabilities. Journal of Human Development, 6(2), 167-183.

O'Reilly, K. (2010). Combining sanitation and women's participation in water supply: An example from Rajasthan. Development in Practice, 20(1), 45-56.

Oduro, G. Y., Swartz, S., \& Arnot, M. (2012). Gender-based violence: Young women's experiences in the slums and streets of three sub-Saharan African cities. Theory and Research in Education, 10(3), 275-294.

Oxfam GB. (2009). Urban Poverty and Vulnerability in Kenya: Background analysis for the preparation of an Oxfam GB Urban Programme focused on Nairobi. 
Parks, M. J. (2014). Urban poverty traps: Neighbourhoods and violent victimisation and offending in Nairobi, Kenya. Urban Studies, 51(9), 1812-1832.

QSR International. (1999). NVivo Qualitative Data Analysis Software. In (Version 12)

Rader, N. E. (2004). The threat of victimization: A theoretical reconceptualization of fear of crime. Sociological Spectrum, 24(6), 689-704.

Rader, N. E., May, D. C., \& Goodrum, S. (2007). An empirical assessment of the "threat of victimization:" Considering fear of crime, perceived risk, avoidance, and defensive behaviors. Sociological Spectrum, 27(5), 475-505.

Rheingans, R., Anderson, J. D., Luyendijk, R., \& Cumming, O. (2014). Measuring disparities in sanitation access: does the measure matter? Tropical Medicine \& International Health, 19(1), 2-13.

Russo, S., \& Roccato, M. (2010). How long does victimization foster fear of crime? A longitudinal study. Journal of Community Psychology, 38(8), 960-974.

Ruteere, M., Mutahi, P., Mitchell, B., \& Lind, J. (2013). Missing the point: Violence reduction and policy misadventures in Nairobi's poor Neighbourhoods.

Sahoo, K. C., Hulland, K. R., Caruso, B. A., Swain, R., Freeman, M. C., Panigrahi, P., \& Dreibelbis, R. (2015). Sanitation-related psychosocial stress: A grounded theory study of women across the life-course in Odisha, India. Social science \& medicine, 139, 80-89.

Sampson, R. J. (2012). Great American City: Chicago and the Enduring Neighborhood Effect. University of Chicago Press.

Shaw, C. R., \& McKay, H. D. (1942). Juvenile delinquency and urban areas. University of Chicago Press.

Shilaho, W. K. (2018). Political power and tribalism in Kenya. Springer.

Stafford, M., Chandola, T., \& Marmot, M. (2007). Association between fear of crime and mental health and physical functioning. American journal of public health, 97(11), 2076-2081.

Stavrou, A. (2002). Crime in Nairobi: results of a citywide victim survey. Un-habitat. 
Swart, E. (2012). Gender-based violence in a kenyan slum: creating local, woman-centered interventions. Journal of Social Service Research, 38(4), 427-438.

UN-Habitat. (2007). Strategy Paper on Urban Youth in Africa.

UN-Habitat. (2015a). Habitat III Issue Paper 22-Informal Settlements.

UN-Habitat. (2015b). Slum almanac 2015-2016: Tracking improvement in the lives of slum dwellers.

UN-Habitat. (2016). Urbanization and development: Emerging Futures (World Cities Report 2016, Issue.

Wanjiru, M. W., \& Matsubara, K. (2017). Slum Toponymy in Nairobi, Kenya. Urban and Regional Planning Review, 4, 21-44.

Warr, M. (1985). Fear of rape among urban women. Social problems, 32(3), 238-250.

Warr, M. (2000). Fear of crime in the United States: Avenues for research and policy. Criminal justice, 4(4), 451-489.

Winter, S., Barchi, F., \& Dzombo, M. N. (2018). Drivers of women's sanitation practices in informal settlements in sub-Saharan Africa: a qualitative study in Mathare Valley, Kenya. International journal of environmental health research, 28(6), 609-625.

Winter, S. C., Dreibelbis, R., Dzombo, M. N., \& Barchi, F. (2019). A mixed-methods study of women's sanitation utilization in informal settlements in Kenya. PloS one, 14(3), e0214114.

Winter, S. C., Obara, L. M., \& McMahon, S. (2020). Intimate partner violence: A key correlate of women's physical and mental health in informal settlements in Nairobi, Kenya. PloS one, 15(4), e0230894.

Wood, S. N., Kennedy, S. R., Hameeduddin, Z., Asira, B., Tallam, C., Akumu, I., Wanjiru, I., Glass, N., \& Decker, M. R. (2019). “Being Married Doesn't Mean You Have to Reach the End of the World": Safety Planning With Intimate Partner Violence Survivors and Service 
Providers in Three Urban Informal Settlements in Nairobi, Kenya. Journal of interpersonal violence, 0886260519879237.

Ziraba, A. K., Kyobutungi, C., \& Zulu, E. M. (2011). Fatal injuries in the slums of Nairobi and their risk factors: results from a matched case-control study. Journal of Urban Health, 88(2), 256-265. 